\title{
EL IMPACTO DE LA CRISIS ECONÓMICA Y DE LA REFORMA CONSTITUCIONAL DE 2012 EN LA JURISPRUDENCIA DE LA CORTE CONSTITUCIONAL ITALIANA EN MATERIA DE PONDERACIÓN ENTRE LOS DERECHOS SOCIALES PRESTACIONALES Y LA ESTABILIDAD PRESUPUESTARIA'
}

The Impact of the Economic Crisis and of the 2012 Constitutional Reform on the Case Law of the Italian Constitutional Court Concerning the Balancing between Fundamental Social Rights and Financial Stability

\author{
PIETRO MASALA ${ }^{2}$ \\ Centro de Estudios Polítcos y Constitucionales \\ pietro.masala@cepc.es
}

Cómo citar/Citation

Masala, P. (2016)

El impacto de la crisis económica y de la reforma constitucional de 2012 en la jurisprudencia de la Corte Constitucional italiana en materia de ponderación entre los derechos sociales prestacionales y la estabilidad presupuestaria. Anuario Iberoamericano de Justicia Constitucional, 20, 223-255. doi: http://dx.doi.org/10.18042/cepc/aijc.20.08

\footnotetext{
1 El autor agradece al profesor Josep Maria Castellà Andreu y a la doctora María Dolores Sánchez Galera su ayuda en la revisión lingüística de este artículo.

2 Pietro Masala es investigador García-Pelayo en el Centro de Estudios Políticos y Constitucionales (Madrid). Licenciado en Derecho por la Universidad de Pisa y doctor en Derecho por la Scuola Superiore Sant'Anna de Pisa (su tesis doctoral obtuvo el Premio Fausto Cuocolo 2011), ha realizado estancias de investigación en las Universidades de Florencia, Sassari, Barcelona y Múnich. Sus principales temas de investigación son el pluralismo territorial y la protección de los derechos sociales en el derecho constitucional nacional, comparado y europeo. Su proyecto de investigación en el marco del programa García Pelayo se centra en el estudio de la «La ciudadanía social europea».
} 


\section{Resumen}

El artículo propone un análisis crítico de la evolución de la jurisprudencia de la Corte costituzionale italiana en materia de ponderación entre las exigencias de protección de los derechos sociales prestacionales y las exigencias de sostenibilidad presupuestaria, particularmente en las situaciones de crísis económica. En concreto se examinan las técnicas de ponderación aplicadas a partir de la última década del siglo XX (en el contexto de la llamada "crisis fiscal del Estado social” y de la introducción de parámetros europeos de sostenibilidad relacionados con las primeras etapas de la Unión Económica y Monetaria europea) y las aplicadas en las decisiones sobre medidas de austeridad adoptadas el marco de la "gran crisis" que empezó en 2008 y de la implementación de la nueva gobernanza económica europea. Su comparación permite averiguar el impacto del nuevo contexto y particularmente el impacto de la constitucionalización del principio de equilibrio presupuestario en 2012.

\section{Palabras clave}

Ponderación constitucional; derechos sociales; estabilidad financiera; Corte Constitucional de Italia; principio de equilibrio presupuestario.

\section{Abstract}

This article analyzes the evolution of the case law of the Italian Constitutional Court concerning the balancing between fundamental social rights and financial stability, particularly in a situation of economic crisis. Therefore, it first examines the techniques of judicial balancing the Court used since the last decade of the XX century (in the context of the "fiscal crisis of the Welfare State" and of the first stages of the European Economic and Monetary Union) and then considers the techniques the Court has used in its recent decisions about austerity measures, in the framework of the new great crisis which started in 2008 and of the implementation of the new European economic governance. This enables to compare them in order to assess the impact of the new context and particularly the consequences of the constitutionalization of the balanced budget principle in 2012 .

\section{Keywords}

Constitutional balancing; social rights; financial stability; Italian Constitutional Court; balanced budget principle. 


\section{SUMARIO}

I. LOS TRIBUNALES CONSTITUCIONALES FRENTE AL RETROCESO DEL ESTADO DE BIENESTAR EN EUROPA; II. LA PONDERACIÓN ENTRE LOS DERECHOS SOCIALES PRESTACIONALES Y LA ESTABILIDAD FINANCIERA EN LA JURISPRUDENCIA DE LA CORTE COSTITUZIONALE ANTES DE LA CRISIS ACTUAL: 1. De la ampliación de la protección a la justificación de su carácter incompleto; 2. El control de razonabilidad de las innovaciones legislativas regresivas. III. LA JURISPRUDENCIA CONSTITUCIONAL EN LOS AÑOS DE LA NUEVA "GRAN CRISIS»: 1. Elementos novedosos del contexto actual: en particular, la constitucionalización del principio de equilibrio presupuestario; 2 . Orientaciones generales; 3 . Decisiones sobre medidas de austeridad. IV. CONCLUSIONES. V. BIBLIOGRAFÍA.

\section{LOS TRIBUNALES CONSTITUCIONALES FRENTE AL RETROCESO DEL ESTADO DE BIENESTAR EN EUROPA}

La crisis económica internacional que empezó en 2008 y la estrategia de respuesta elegida por la Unión Europea, cuya prioridad absoluta ha sido y sigue siendo la salvaguardia de la estabilidad financiera, han tenido repercusiones especialmente significativas sobre los ordenamientos de los Estados miembros de la Unión Económica y Monetaria, puesto que dentro de esta nuevos acuerdos intergubernamentales han reforzado los parámetros relativos al déficit y a la deuda pública, fortaleciendo la coordinación de las políticas presupuestarias e introduciendo nuevos mecanismos de rescate (Donati, 2013).

Los efectos han sido más pronunciados en aquellos países que, debido a su situación económica y financiera, han sido más vulnerables y han pedido ayudas en la fase más aguda de la crisis. Conforme a criterios de estricta condicionalidad, su concesión se ha sujetado al compromiso para adoptar reformas incisivas en la esfera económica y social, fijadas por acuerdos suscritos entre los Gobiernos e instituciones carentes de legitimación democrática (Comisión Europea, BCE, FMI), que han sido investidas del poder de control para garantizar su cumplimiento. La contrapartida de la solidaridad financiera han 
sido fuertes limitaciones de la soberanía de los Estados «beneficiarios» sobre la gestión de las políticas sociales, para garantizar la implementación de una dirección política "condicionada» cuyos objetivos primarios, conforme a la ideología subyacente en las reglas de la nueva gobernanza económica europea, son la contención del gasto público y la flexibilización laboral. Además, la exigencia de dar rápida aprobación a medidas impopulares (para ejecutar los acuerdos adoptados o, en su ausencia, para alejar el espantajo de ingerencias externas más profundas) ha causado una grave alteración de los equilibrios de la democracia representativa, favoreciendo un marcado fortalecimiento de los Ejecutivos y una correspondiente marginalización de los Parlamentos, particularmente con respecto al ejercicio de la función legislativa. Cambios profundos han afectado de este modo a la fórmula del Estado social y democrático de derecho consagrada en las constituciones de la posguerra. Aunque tendencias parecidas, favorecidas por la integración europea, ya se habían manifestado, el nuevo contexto ha supuesto un salto de calidad evidente; e incluso, en los casos de España e Italia, las propias constituciones han sido reformadas para reconocer expresamente el principio de sostenibilidad o equilibrio presupuestario ${ }^{3}$.

Con respecto al caso italiano, no ha habido acceso a los fondos de rescate; sin embargo, parece correcto afirmar que la «solidaridad condicionada» ha tomado una forma diferente pero no menos eficaz. El BCE ha intervenido repetidamente, adquiriendo ingentes cantidades de títulos de deuda pública; asimismo, en verano de 2011, indicó, por medio de una carta dirigida al jefe de Gobierno, un programa de reformas de inspiración neoliberal, especificando los tiempos y formas para su implementación. Los Gobiernos que se han sucedido han realizado gran parte de ese programa, que incluía medidas de contención del gasto público, especialmente social, y de flexibilizacion laboral (Olivito, 2014). En general, durante la legislatura pasada y la presente, la referencia a las orientaciones fijadas a nivel europeo ha servido para legitimar no solo la adopción de medidas nacionales de austeridad y flexibilización laboral, sino también el creciente protagonismo del Gobierno en el ejercicio de la función legislativa. Tanto los contenidos de la legislación como las modalidades de su ejercicio han sido influenciados fuertemente por el nuevo contexto, en el que los parámetros europeos de estabilidad y el paradigma de la «flexiguridad» han visto reforzar su capacidad para condicionar y legitimar a los legisladores nacionales (Masala, 2016).

3 Para ejecutar las previsiones del Tratado de Estabilidad, Coordinación y gobernanza («Fiscal compact», suscrito en marzo de 2012), aunque el apartado 2 de su art. 3 permitía opciones alternativas a la revisión constitucional. 
En el mismo contexto, la Corte costituzionale italiana y las de los demás países que se han «beneficiado» de ayudas se encuentran en una posición que exalta su papel, pero a la vez es incómoda. Por un lado, hacia estas Cortes se dirigen las expectativas de quienes, frente a la legislación «ejecutiva» que ha redimensionado el Estado social, ven en ellas el último baluarte capaz de resistir y restaurar, al menos parcialmente, los equilibrios alterados. Sin duda, la superación de la austeridad supone un acuerdo político a nivel supranacional para fundar la prosecución del proceso de integración sobre nuevas bases de legitimación democrática. No obstante, queda igualmente claro que, a falta de eso (y del desarrollo del papel de las Cortes supranacionales, que todavía parecen ser incacapaces de proteger eficazmente los derechos sociales: Guazzarotti, 2013) los tribunales constitucionales nacionales seguirán desempeñando un papel insuficiente pero hasta ahora irremplazable para reducir sus elevados costes sociales. Por otro lado, el control de constitucionalidad de las medidas de austeridad implica una difícil ponderación entre las exigencias de protección de los derechos (y de las prerrogativas de los Parlamentos y de las autonomías territoriales) y la exigencia de salvaguardar la estabilidad financiera en el marco de una crisis económica grave y persistente. Es esta una tarea muy delicada, por los posibles efectos de las decisiones de los tribunales sobre las finanzas públicas y sobre la capacidad de los Estados para cumplir con los parámetros europeos (y con los compromisos pactados a cambio de ayuda). De ahí posibles tensiones con los órganos políticos, especialmente con los Gobiernos, que son responsables frente a las instituciones europeas y han adoptado esas medidas o impuesto su aprobación a los Parlamentos.

En la parte central de este estudio se analizará la jurisprudencia de la Corte costituzionale sobre las medidas de estabilización financiera adoptadas en el contexto de la reciente crisis económica. Se considerará la reacción de la Corte frente a la limitación de los derechos sociales en la emergencia.

Evidenciando las orientaciones y los esquemas de razonamiento utilizados en el control de la discrecionalidad política y legislativa y los resultados de su aplicación, se tratará de entender si ha prevalecido una actitud de contraposición o, por el contrario, de prudente autolimitación. Para fundamentar la valoración que se va a expresar, previamente se ilustrarán las orientaciones establecidas en los años noventa del siglo xx, cuando, en una situación de crisis financiera, la Corte ya tuvo que decidir sobre innovaciones legislativas que reducían la protección ya garantizada. En las conclusiones se compararán las orientaciones más recientes con las establecidas anteriormente, a fin de averiguar si hay continuidad o, por el contrario, en qué medida los elementos peculiares del contexto actual, y en concreto la constitucionalización del principio de equilibrio presupuestario a partir de 2012, han tenido repercusiones sobre los argumentos y las técnicas de decisión utilizados. 


\section{LA PONDERACIÓN ENTRE LOS DERECHOS SOCIALES PRESTACIONALES Y LA ESTABILIDAD FINANCIERA EN LA JURISPRUDENCIA DE LA CORTE COSTITUZIONALE ANTES DE LA CRISIS ACTUAL}

\section{DE LA AMPLIACIÓN DE LA PROTECCIÓN A LA JUSTIFICACIÓN DE SU CARÁCTER INCOMPLETO}

A la hora de analizar la jurisprudencia constitucional en materia de derechos sociales, resulta indispensable periodificar. De hecho, en el tiempo comprendido entre el inicio de la actividad de la Corte costituzionale y el inicio de la reciente "gran crisis", hay que distinguir dos fases principales.

En la primera, que coincide, aunque sea aproximadamente, con los «Treinta Gloriosos» de la posguerra, también en Italia se desarrolla, no sin dificultad, la construcción de un moderno sistema de protección social conforme al programa constitucional basado en los principios de solidaridad e igualdad sustancial (arts. 2 y $3.2 \mathrm{CI}$ ). El problema principal es entonces encontrar remedios frente a las omisiones legislativas en la implementación de las normas constitucionales "programáticas» sobre los derechos sociales. Para garantizar la al menos parcial preceptividad de dichas normas en caso de protección legislativa ausente o insuficiente, la Corte utiliza abundantemente las llamadas «sentencias aditivas de prestación»: decisiones manipulativas con las que, cuando tenga que controlar la constitucionalidad de disposiciones que proporcionan la implementación parcial de un derecho prestacional, y acabe considerando insuficiente la protección garantizada (a la luz de un juicio basado en el art. 3.1 CI o, con menor frecuencia, en el art 3.2 CI y en las normas constitucionales sobre los derechos sociales), la propia Corte amplía el alcance de dicha protección: normalmente extendiendo o generalizando prestaciones que el legislador había previsto en favor de una categoría determinada de beneficiarios (Butturini, 2014).

$\mathrm{El}$ «intervencionismo» de la Corte que se dirige a salvaguardar los derechos sociales alcanza su pico máximo en 1987-1988 (Benvenuti, 2013: 115). Sin embargo, ya a partir de la década de los ochenta (aunque los primeros signos aparecen ya con la recesión relacionada con la crisis petrolera de 1973), nuevos equilibrios internacionales y nuevas condiciones económicas contribuyen a determinar un "cambio de perspectiva» radical, a nivel político y cultural, que se refleja en el debate doctrinal y causa un rápido cambio también en la jurisprudencia constitucional (Luciani, 2013a: 6). Es preciso centrarse en esta segunda fase, que es ya de crisis en varios aspectos: "crisis fiscal» del Estado de bienestar, cuya trayectoria de expansión ya ha terminado; crisis de los paradigmas culturales que habían acompañado esa trayectoria, a los que 
se oponen nuevas escuelas de pensamiento, que propugnan la limitación de esa forma de Estado; por último, crisis económica y financiera en la última decada del siglo xx, mientras se estabecen las bases de la Unión Económica y Monetaria. Mientras una nueva recesión se produce en los años 1992-1993, la participación en el proyecto europeo implica políticas de contención del gasto, para garantizar el cumplimiento de los parámetros fijados por el Tratado de Maastricht de 1992 y reafirmados por el Pacto de Estabilidad y Crecimiento de 1997.

En el nuevo contexto destacan dos nuevas cuestiones, ambas relacionadas con la conciliación entre la protección de los derechos sociales prestacionales («costosos», al igual que todos los derechos, pero supuestamente «más costosos») y las exigencias financieras. El debate concierne, en primer lugar, a los efectos presupuestarios de las decisiones aditivas de prestación; además concierne, en la fase de recesión y «sacrificios» requeridos por la adhesión a la UEM, a los límites de admisibilidad de innovaciones legislativas regresivas en cuanto a la protección de los derechos. En la jurisprudencia constitucional el cambio se produce en los noventa (Colapietro, 1996; Salazar, 2000).

El debate sobre las «sentencias constitucionales costosas» (impulsado por la propia Corte, que en 1991 organizó un congreso dedicado al tema: VV. AA., 1993) se articulaba en dos niveles: la admisibilidad de dichas sentencias y el supuesto deber de la Corte de valorar el impacto económico de sus propias decisiones, ponderando la protección de los derechos con la salvaguardia del equilibrio financiero. La opinión de quienes no consideraban en absoluto admisibles decisiones que conllevaran un incremento del gasto público resultó ser minoritaria. A quienes pretendían que las decisiones de la Corte fueran sometidas al «antiguo» art. $81.4 \mathrm{CI}$ (conforme al cual cualquier ley que conllevara «nuevos o mayores gastos» debía «indicar los medios para proveerlos»), se podía facilmente oponer que dicho precepto se dirigía exclusivamente al legislador y que las sentencias contitucionales, siendo actos jurisdiccionales (resultado de una evaluacíon que no es discrecional y política, sino lógica y jurídica: Pizzorusso, 1993), no son asimilables a la ley: de modo que, si las sentencias de la Corte "cuestan», no es esta quién debe indicar la manera de cubrir los gastos, sino que deben hacerlo el Parlamento y el Gobierno (Luciani, 1993). También en cuanto al deber de la Corte de valorar el impacto económico de sus propias decisiones a fin de salvaguardar el equilibrio financiero (deber supuestamente fundado en el mismo precepto), se enfrentaron opiniones diferentes (VV. AA., 1993). La novedad más destacada fue que se afirmaron tesis que, poniendo el acento en la naturaleza "condicionada" - por la intermediación legislativa y por la disponibilidad de recursos- de los derechos prestacionales, pretendían proporcionar fundamentos para redimensionar tanto el Estado social como el papel de la Corte. Así, Baldassarre (1989) distinguía 
entre derechos sociales no condicionados (de estructura análoga a la de las clásicas libertades) y condicionados (prestacionales, cuyo disfrute depende de la necesaria interpositio legislatoris); mientras que Merusi (1985) calificaba los derechos prestacionales de "derechos financiariamente condicionados», cuyo disfrute debe asegurarse de manera compatible con las disponibilidades de gasto y dentro de los límites del gasto programado ${ }^{4}$.

De hecho, la Corte fue inducida (también por las reacciones polémicas, especialmente del Gobierno, a unas decisiones "costosas») no solo a valorar con mayor atención el impacto financiero de sus decisiones, sino también a "cambiar drásticamente su sensibilidad» (Benvenuti, 2013: 116), con repercusiones sobre sus orientaciones y sobre sus técnicas decisorias. El momento crucial suele reconocerse en la Sentencia 455/1990, sobre el derecho a las prestaciones sanitarias, donde se afirma la doctrina de los derechos sociales prestacionales como "derechos financieramente condicionados». Aunque dicha expresión no se utiliza, se afirma que los derechos prestacionales, por fundarse «en normas constitucionales programáticas que establecen una finalidad determinada», son garantizados como «derechos constitucionales condicionados por la implementación legislativa, que supone la ponderación» de los intereses subyacentes «con los demás intereses constitucionalmente protegidos, teniendo en cuenta los límites objetivos que el propio legislador encuentra en sua obra de implementación con respecto a los recursos organizativos y financieros disponibles». La exigencia de una "ponderación razonable», particularmente «con la posibilidad real y objetiva de disponer de los recursos necesarios», implica que dicha implementación puede legítimamente ser "gradual», es decir incompleta 5 .

A pesar de las críticas puestas por unos constitucionalistas (porque no sería correcto hablar de "ponderación» entre un derecho constitucional, que representa un fin, y los recursos disponibles, que son un medio: de modo que se trataría de una "ponderación desigual»: Luciani, 1995; Bin, 1992: 109), la Corte ha confirmado esta doctrina, que se ha traducido en una actitud muy prudente, casi siempre deferente, en el control de «razonabilidad» de la ponderación realizada por el legislador. En la posterior jurisprudencia constitucional sobre los

4 También puede reconocerse, en tales tesis, la sugestión de la conocida doctrina de la «reserva de lo razonable y de lo posible» del Bundesverfassungsgericht alemán.

5 Cfr. fundamento 3 de la decisión. El redactor de la sentencia fue A. Baldassarre. La Sentencia 252/1989 había ya afirmado que, "tal y como cualquier derecho social», el derecho a la vivienda «tiende a ser realizado en proporción a los recursos de la colectividad» y que «solo el legislador, midiendo las disponibilidades reales y los intereses que mediante estas pueden ser gradualmente satisfechos, puede racionalmente proveer a relacionar medios y fines, y construir puntuales situaciones justiciables». 
derechos sociales prestacionales la tendencia a la autolimitación ha prevalecido (Salazar, 2000: 100): la Corte normalmente ha otorgado prioridad a las exigencias de equilibrio financiero, reconociendo un amplio margen de discrecionalidad en favor del legislador (lo demuestra especialmente la jurisprudencia sobre el derecho a las prestaciones sanitarias: Masala, 2014b). La ponderación legislativa ha sido declarada inconstitucional solo cuando ha sido considerada manifiestamente arbitraria o perjudicial para el contenido esencial del derecho.

El control de la discrecionalidad legislativa se ha desarrollado preferentemente conforme a los esquemas del control de razonabilidad. Solo raramente se han fundado declaraciones de inconstitucionalidad por violación del principio de igualdad sustancial (art. 3.2 CI) o de las normas constitucionales sobre los derechos sociales; y normalmente, incluso en este supuesto, la Corte ha constadado la violación del principio de razonabilidad (art. 3.1 o genéricamente art. $3 \mathrm{CI}$ ).

En cuanto al límite del contenido esencial, en general su violación se da cuando el interés subyacente del derecho es comprimido de una manera tan acentuada que resulta prejudicada su "operatividad mínima», constitucionalmente exigida (Bin, 1992: 103, con fórmula utilizada en la Sentencia 28/1982). La Corte ha constatado dicha violación en pocos casos, relativos principalmente al derecho a las prestaciones sanitarias (varias decisiones han incluido en su contenido esencial el derecho a disfrutar siempre de las prestaciones indispensables, urgentes e indiferibles y el derecho de los «indigentes» que se encuentren temporalmente en el extranjero a formas de asistencia gratuita: Masala, 2014b: 21), sin definir la noción. En la doctrina, aunque se aprecia «la intención de dar un fundamento sustancial» a la protección de los derechos sociales, se han subrayado las dificultades relacionadas, ya sean «conceptuales» o "prácticas», confirmadas por el análisis de la jurisprudencia constitucional (Benvenuti, 2013: 139-142). En concreto, se ha observado que el contenido esencial no suele ser definido como premisa objetiva del juicio de ponderación, sino que su violación suele ser deducida posteriormente (Andreoni, 2006: 296); se ha evidenciado su función «retórica»(e integradora de decisiones que están ya fundadas en la violación del art. 3.1 CI) y además el riesgo de que en su determinación casuística prevalezca una concepción «relativa» y «reduccionista» (Massa Pinto, 1998 y 2001) ${ }^{6}$; se ha denunciado, por último, su naturaleza «huidiza» e «inaprensible» (Salazar, 2013: 809).

6 Una interpretación reduccionista se da en la Sentencia 304/1994, donde se afirma que el núcleo esencial del derecho a la salud sería perjudicado solo cuando «las exigencias relativas al equilibrio financiero [...] tengan un papel absolutamente preponderante» y se dé «un ejercicio macroscópicamente irrazonable de la discrecionalidad legislativa». 
La evolución descrita de las estrategias argumentativas ha ido acompañada por la diversificación de las técnicas decisorias. En concreto, se han experimentado nuevos tipos de decisión que hacen manifiesta la preocupación por las tensiones con el poder político. En unos casos, la Corte, en lugar de declarar inmediatamente inconstitucional la regulación legislativa insuficiente, ha dirigido una advertencia al legislador, invitándole a intervenir para remediar la situación; en otros casos, se han usado formas de limitación de los efectos temporales de la decisión, como las «declaraciones de ilegitimidad sobrevenida». Incluso cuando la Corte no ha utilizado dichas técnicas, las sentencias aditivas de prestación han sido remplazadas por las aditivas «de principio»: decisiones que son más respetuosas de la discrecionalidad legislativa y menos impactantes económicamente (además de capaces de asegurar una justiciabilidad parcial de los derechos cuando la adición de una prestación resulta imposible (sobre estas técnicas: Benvenuti, 2013: 129-136).

\section{EL CONTROL DE RAZONABILIDAD DE LAS INNOVACIONES LEGISLATIVAS REGRESIVAS}

Al mismo tiempo que se asentaba la doctrina que justificaba la «gradualidad» de la implementación de los derechos sociales prestacionales, en los años noventa se iba consolidando otra doctrina conforme a la cual innovaciones legislativas regresivas (que reducen la protección ya garantizada), no son en sí ilegítimas. También en los juicios sobre medidas de este tipo la Corte costituzionale tiende a autolimitarse, imponiendo como únicos límites de la discrecionalidad legislativa la razonabilidad y la salvaguardia del contenido esencial de los derechos afectados (sobre los límites de la reversibilidad in malum de la legislación social: Midiri, 2011; Benvenuti, 2013, 137-139).

Varias decisiones afirman que intervenciones dirigidas a redimensionar la legislación social pueden justificarse por la exigencia de contener el gasto público. En concreto, se confirma que, a la luz de los recursos disponibles, puede admitirse una reducción definitiva de los tratamientos de jubilación (consiguiente a la modificación de los criterios de cálculo o de los requisitos para conseguirlos), siempre y cuando no sea arbitraria. En consonancia con los principios afirmados por la Sentencia 455/1990, la Sentencia 119/1991 establece que el derecho a un tratamiento de jubilación proporcionado y adecuado debe implementarse mediante una ponderación razonable que tenga en cuenta dicha limitación ${ }^{7}$. La sentencia 390/1995 afirma que «en nuestro sistema constitucional no se prohíbe al legislador adoptar disposiciones que

7 Véase también la Sentencia 240/1994. 
modifiquen en un sentido desfavorable para los beneficiarios la regulación de las relaciones de larga duración, aún cuando sus derechos subjetivos perfectos constituyan su objeto»; especificando que la «única condición esencial es que dichas disposiciones no excedan hasta suponer una regulación irracional, frustrando, con respecto a situaciones sustanciales fundadas en leyes anteriores, la confianza del ciudadano en la seguridad jurídica, considerada como elemento fundamental del estado de derecho». Estas premisas justifican modificaciones peyorativas dirigidas a asegurar el "equilibrado curso presupuestario» de las cajas de la seguridad social.

Todo esto permite observar diferencias significativas con respecto a la Sentencia 822/1988: ya sea con referencia a la formulación del principio ${ }^{8}$ o por el fallo. La decisión de 1988 había declarado ilegítima, por ser irracional y lesiva del art. $3 \mathrm{CI}$, una disposición que introducía nuevos criterios de cálculo en la parte en que no aseguraba, en favor de los trabajadores próximos a jubilarse por vejez, o ya jubilados, la aplicación de los criterios más favorables previstos por la regulación anterior. En ese caso, la Corte había considerado «las exigencias de contención del gasto de la seguridad social» como «razones no idóneas para justificar la reducción de la pensión en perjuicio de aquellos trabajadores que han cotizado sus cuotas de la seguridad social, en todo o en parte, conservando la expectativa legítima de conseguir un tratamiento adecuado»; también había subrayado la exigencia de aplicar, a favor de los mismos trabajadores, «el principio de la garantía de la seguridad social, que es igualmente de relevancia constitucional (art. 38), además de las innegables razones de justicia social y de equidad que implican que no pueden adoptarse reformas ni conseguirse resultados en daños de categorías de trabajadores, especialmente de los que estén cercanos a la jubilación o ya jubilados». La Sentencia 417/1996 confirma el cambio de actitud de la Corte, especificando que, conforme a su jurisprudencia, los arts. 36 y $38 \mathrm{CI}$ «no excluyen la legitimidad de una intervención legislativa que, por exigencias inderogables de contención del gasto público, reduzca definitivamente un tratamiento de jubilación anteriormente previsto, teniendo en cuenta los recursos disponibles» y que, «en el ámbito de la programación presupuestaria, pertenece al Gobierno y al Parlamento modificar la legislación de gasto, cuando sea preciso para

8 La Sentencia 822/1988 especificaba que, puesta la inadmisibilidad de intervenciones «absolutamente discrecionales», «no es permitida una modificación que, interveniendo o en una fase avanzada de la relación de trabajo o cuando ya sea sobrevenido el estado de quiescencia, empeore, sin una exigencia inderogable, en medida irrazonable y de manera definitiva, un tratamiento de seguridad social». 
salvaguardar el equilibrio del presupuesto del estado y perseguir los objetivos de la programación financiera».

Al mismo tiempo se consolida la doctrina conforme a la cual, no solo en el ámbito de la seguridad social, medidas que implican un retroceso respecto a la protección asegurada por leyes anteriores pueden admitirse en una situación de crisis financiera. La Corte utiliza nuevas estrategias argumentativas, manifiestamente influenciadas por el contexto de crisis y por la exigencia de garantizar el cumplimiento de los parámetros de la UEM. Varias decisiones especifican que sacrificios, incluso gravosos, justificados por la exigencia de salvaguardar el equilibrio financiero, son legítimos siempre y cuando no sean irrazonablemente duraderos ni irracionalmente repartidos entre diferentes categorías de ciudadanos: conforme a estos criterios se consideran razonables unas disposiciones que reducen las rentas de los jubilados y de los empleados públicos.

La referencia a los requisitos de temporalidad y provisionalidad de las medida regresivas se encuentra en la Sentencia 99/1995, que declara infundada una cuestión de constitucionalidad relativa a una disposición de la Ley 537/1993, que había diferido hasta 1995 los incrementos de las pensiones de jubilación determinados por el mecanismo de perecuación previsto por leyes anteriores. Dicha disposición había sido impugnada por ser supuestamente lesiva del principio de igualdad (art. $3 \mathrm{CI}$ ) y de los requisitos de proporcionalidad y adecuación de la retribución (arts. 36 y 38 CI) $)^{9}$. Igualmente, la Sentencia 245/1997 declara infundada la impugnación, por supuesta disparidad de trato injustificada, de una norma del decreto-ley que había suspendido durante 1993 los incrementos retributivos automáticos de los empleados públicos ${ }^{10}$. Notable, en los fundamentos, es la referencia a los condicionamientos financieros derivados de la adhesión a la UE: la Corte subraya que la medida de «bloqueo» estaba prevista por un acto «adoptado en un momento delicado de la vida nacional», mediante el cual se habían aprobado «varias disposiciones dirigidas a conseguir, con inmediatez, la contención del gasto público de 1993, de conformidad con los objetivos fundamentales de política económi-

9 Puesto que "pertenece al legislador, en el ejercicio equilibrado de su discrecionalidad y considerando también las exigencias fundamentales de política económica [...] ponderar todos los factores constitucionalmente relevantes», se advierte que el proceso de revalorización "solo es diferido para un periodo razonablemente contenido», con «fundamento en la más amplia definición de las metas de las finanzas públicas».

10 Art. 7.3 del decreto ley 384/1992. La Corte observaba que el bloqueo, evidentemente «excepcional, agotaba sus efectos en el año considerado, limitándose a impedir erogaciones por exigencias de reequilibrio presupuestario, protegidas mientras y cuando la disposiciones adoptadas no resulten arbitrarias». 
ca y de los compromisos derivados del proceso de integración europea». La Ordenanza 299/1999, al declarar manifiestamente infundada otra cuestión referida a la misma disposición, lo sintetiza eficazmente, precisando que: «por exigencias tan urgentes» como la «necesidad de recuperar el equilibrio presupuestario», "en un momento muy delicado de la vida económica y financiera del país», normas que impongan «a todos sacrificios, incluso gravosos» son «no lesivas del principio del art. 3 de la Constitución (tanto con referencia a la igualdad sustancial como con referencia a la razonabilidad), siempre y cuando dichos sacrificios sean excepcionales, transitorios, no arbitrarios y ajustados al fin establecido».

\section{LA JURISPRUDENCIA CONSTITUCIONAL EN LOS AÑOS DE LA NUEVA «GRAN CRISIS»}

\section{ELEMENTOS NOVEDOSOS DEL CONTEXTO ACTUAL: EN PARTICULAR, LA CONSTITUCIONALIZACIÓN DEL PRINCIPIO DE EQUILIBRIO PRESUPUESTARIO}

El análisis desarrollado permite entender por qué quien ha estudiado asiduamente la jurisprudencia constitucional sobre los derechos sociales ha observado que, cuando empieza la reciente crisis económica, «la extensión de la gradualidad en la implementación de los derechos costosos, el retroceso o el avance respecto de la protección ya garantizada, la reducción o la ampliación de los beneficiarios, son desde hace tiempo elementos ordinariamente no cuestionables». Las tendencias consolidadas desde la década de los noventa han llevado a constatar, que aunque «una de las implicaciones más problemáticas del juicio de razonabilidad consiste en el riesgo de que la Corte, en vez de controlar la legitimidad de la ley, acabe controlando la oportunidad de la propia decisión legislativa», en el ámbito considerado «la aplicación del test de razonabilidad ha acabado conteniendo y no ampliando la extensión del control» (Salazar, 2013: 811).

Antes de analizar la jurisprudencia más reciente es oportuno destacar los principales elementos novedosos del contexto actual, de modo que luego pueda valorarse su influencia en las decisiones sobre las medidas de estabilización financiera que han afectado los derechos sociales. Aunque existen varias analogías con la crisis de los noventa, no solo la actual es más grave y persistente, sino que también ha conllevado una reestructuración de la gobernanza económica de la UE muy impactante, ya que los compromisos presupuestarios se han fortalecido y se ha incrementado su capacidad para condicionar (y legitimar) las políticas nacionales en la esfera económica y social, sobre todo en los 
países de la eurozona que se han «beneficiado» de ayudas. Entre estos hay que incluir a Italia, aunque, como ya se ha indicado, la «solidaridad condicionada» ha tomado una forma peculiar.

En concreto, es preciso considerar las implicaciones de la Ley Constitucional 1/2012, que, con la finalidad de ejecutar el nuevo "pacto presupuestario» europeo ${ }^{11}$, ha modificado el art. $81 \mathrm{CI}$, introduciendo, en su apartado 1 , el principio conforme al cual «el Estado asegura el equilibrio entre los ingresos y los gastos de su presupuesto, teniendo en cuenta las fases desfavorables y las fases favorables del ciclo económico». En cambio, en el apartado 4 del mismo artículo, se confirma que «cualquier ley que conlleve nuevas o mayores cargas debe proveer los medios para hacerles frente».

Se ha señalado que la fórmula utilizada en el nuevo apartado 1 (equilibrio di bilancio - equilibrio presupuestario-), aunque permite varias interpretaciones, es sin duda "menos rígida» que la del pareggio di bilancio («igualación del presupuesto»), utilizada exclusivamente en el título de la ley constitucional, y parece dejar «amplios márgenes de discrecionalidad a los órganos de dirección política, permitiendo decidir conforme a la situación económica concreta» (Salazar, 2013: 802, teniendo en cuenta que el nuevo art. 81.2 CI permite el endeudamiento, aunque solo en determinados supuestos, especificados por el art. 6, Ley 243/2012; el nuevo marco constitucional mantiene, en buena medida, la «original ductilidad» según Luciani, 2013a: 43). Eso no supone que la reforma («innecesaria», ya que el Fiscal Compact permitía soluciones jurídicas alternativas a la revisión constitucional, que fue la consecuencia de la debilidad financiera del país) sea «insignificante»: puesto que ha introducido nuevos parámetros que tienen impacto en el control de constitucionalidad (Luciani, 2013a: 22-30). Hay que establecer, en particular, si la constitucionalización del principio de equilibrio presupuestario implica nuevas limitaciones para la jurisdicción de la Corte costituzionale en el ámbito considerado, es decir, si la reforma ha reducido sus márgenes de evaluación cuando controle disposiciones que implementen «gradualmente» los derechos sociales o reduzcan su protección. La cuestión ha interpelado a los estudiosos ya antes de que las nuevas normas constitucionales fueran aplicadas y evocadas en las argumentaciones de los magistrados constitucionales ${ }^{12}$.

11 Conforme al art. 3 del Fiscal Compact, la regla del equilibrio presupuestario debería producir efectos en el derecho nacional «mediante disposiciones vinculantes y de carácter permanente — preferiblemente constitucional— o cuya observancia fiel sea garantizada rigurosamente a lo largo del proceso presupuestario nacional».

12 El art. 6 de la Ley Consitucional 1/2012, previó que las nuevas disposiciones constitucionales se aplicarían «a partir del ejercicio presupuestario de 2014». 
Quienes hace dos décadas habían negado el sometimiento de las decisiones de la Corte al precepto del antiguo art. 81.4 CI, excluyen hoy que, aun después de la reforma, la exigencia de equilibrio presupuestario pueda impedir que se fallen sentencias costosas, puesto que el nuevo art. $81 \mathrm{CI}$ sigue imponiendo a la sola ley la obligación de proveer. En cambio, en cuanto al supuesto deber de la Corte de tener en cuenta el impacto de dichas sentencias, se ha deseado una reflexión «sobre la oportunidad de reenviar con mayor frecuencia a la discrecionalidad legislativa o sobre la modulación en el tiempo de los efectos de las decisiones estimatorias», como alternativas a la ponderación, técnica desaconsejada ya sea por su "problemática compatibilidad con el principio de certeza del derecho» que por su «desigualdad», cuando sea entre recursos y derechos (Luciani, 2013b: 32-34).

Algunos han expresado preocupación por las posibles consecuencias de la introducción del principio de equilibrio presupuestario en la Constitución, en concreto para la protección de los derechos sociales (Grasso, 2012: 151). De hecho, si se interpreta la constitucionalización como la indicación de un fin para el legislador, al igual que la implementación de los derechos, resulta más difícil oponer, a quienes afirman que la Corte debería valorar más rigurosamente el impacto económico de sus decisiones, el argumento de la naturaleza «desigual» de la ponderación entre derechos y recursos. Ya antes de la reforma, dicho argumento no ha impedido la consolidación de la tendencia a la autolimitación en la jurisprudencia constitucional sobre los derechos prestacionales. Pues hoy hay más razones para temer la absoluta preponderancia de las exigencias financieras en los razonamientos de los magistrados constitucionales. A esta posibilidad se ha opuesto que, incluso tras la reforma, el equilibrio financiero no tiene "el rango de valor constitucional», sino que es «una simple regla» que no puede «suplantar» los derechos, que constituyen «limites constitucionales insalvables» (Grasso, 2012: 156).

Algunos, en cambio, han propuesto una interpretación «irénica» de la reforma: poniendo el acento en los márgenes de flexibilidad del nuevo art. 81 $\mathrm{CI}$, por los que quedaría salvaguardado el contenido esencial de los derechos; y señalando que una gestión más rigurosa del gasto público «no implica en sí un indiscriminado sacrificio de las garantías sociales», sino que debería inducir al legislador a establecer una «progresiva reasignación de los recursos» según criterios de mayor selección y equidad, justificados por la exigencia de asegurar la sostenibilidad del Estado social (Giupponi, 2014: 68-69). Califica expresamente su propia interpretación de «irénica» Morrone (2014a), considerando que «el programa constitucional de promoción de la igualdad puede implementarse mediante reglas estrictas de gestión presupuestaria» y que el equilibrio presupuestario, tal y como se ha positivizado, «desarrolla una función constitucional de salvaguardia de los derechos de ciudadanía inclusiva e 
intergeneracional». Incluso (para Morrone, 2014b: 90 y 99-108), el equilibrio presupuestario sería «condición para la realización del Estado de bienestar» y para "la supervivencia del Estado constitucional», ya que es «condición para la Unificación política de Europa» (también pone el acento en las razones de la sostenibilidad, como condición para la realización de auténticas instancias de justicia social, Spadaro, 2011). Si interpretaciones de este tipo parecen suponer que la Corte no debería obstaculizar obras de «reestructuración» de la legislación social dirigidas a ese fin (siempre y cuando sea salvaguardado el contenido esencial de los derechos), otros han indicado que poner el acento en las razones («buenas») de la sostenibilidad podría dificultar la defensa de los derechos «frente a políticas públicas que utilizan la crisis económica para reducir su protección y efectividad y frente a un mercado global que dilata las desigualdades», y han insistido en que los derechos no son solo un coste, sino también un «recurso» en el que hay que invertir para salir de la crisis (Grasso, 2012: 156; Ciolli, 2012: 24). A la luz de las formas reales de la intervención legislativa reciente (que, ya antes de la reforma, había implicado frecuentes recortes «lineales», injustos por definición: Morana, 2013), se han propuesto soluciones para contrastar la tendencia a cargar los costes de la crisis sobre el Estado de bienestar y para recuperar la centralidad de los derechos en las políticas públicas. Desde esta perspectiva, se ha insistido, en primer lugar, en que el legislador funde la asignación de los recursos escasos en la consideración de las prioridades establecidas por la Constitución, a partir de los arts. 2 y 3.2 y de los derechos sociales; en segundo lugar, en que la Corte garantice la coherencia entre las asignaciones legislativas y las prioridades constitucionales. En concreto, se invita a distinguir entre asignaciones constitucionalmente debidas, permitidas y prohibidas (Carlassare, 2013: 3 y 7). Desde la misma perspectiva, se ha invitado a distinguir, dentro de las «sentencias costosas», las que extiendan tratamientos más favorables de las que «necesariamente apliquen principios constitucionales violados»: para excluir que el límite de los recursos disponibles pueda imponerse a las segundas (Carlassare, 2013: 9, observando que mientras que las decisiones que disponen una "parificación hacia arriba» se basan en un juicio «inevitablemente discrecional», en el otro caso se trata de «imponer el cumplimiento de normas constitucionales vinculantes»).

Tales propuestas, que insisten en la centralidad del programa del art. 3.2 CI (y suponen una concepción «expansiva» de la Constitución y de los derechos) evidentemente no coinciden con las opiniones de quienes, insistiendo en la exigencia de asegurar la sostenibilidad, admiten la reversibilidad parcial de la legislación social. Sin embargo, tampoco las distintas posiciones parecen irreconciliables sin remedio. Insistir en que los recursos, conforme al dato constitucional, sean asignados de acuerdo con las prioridades que convergen en salvaguardar el «valor central» de la persona y de su dignidad no significa 
negar la exigencia de eliminar despilfarros y privilegios injustos; igualmente, insistir en que la legislación social deba corregirse según criterios de mayor equidad y selección no implica indiferencia hacia la exigencia de proteger los derechos.

Por último, resulta fundamental establecer qué correcciones son admisibles. En concreto, si todos comparten la exigencia de salvaguardar el contenido esencial de los derechos, es preciso definir el alcance de dicho contenido. El esfuerzo se impone especialmente a la Corte costituzionale, cuando esta controle la constitucionalidad de intervenciones reductoras y por lo tanto tenga que establecer, con referencia a los casos examinados, las protecciones que no admiten reversibilidad y los límites que no pueden ser traspasados por la discrecionalidad legislativa, incluso en un contexto de crisis y después de la reforma constitucional. Además, parece correcto señalar que, en un contexto de recursos fuertemente reducidos, resulta aún más imprescindible que el legislador no persiga la estabilidad financiera como un fin en sí mismo, en perjuicio del cumplimiento de las "prioridades constitucionales». En cambio, esta debe perseguirse como medio para conseguir ese fin último. Eso significa que la repartición de los recursos escasos y de los sacrificios no debe contradecir los principios fundamentales de solidaridad, de igualdad sustancial y personalista. Si las decisiones distributivas reflejan una "voluntad política», y si la de cargar gran parte del coste de la crisis sobre el Estado de bienestar ha sido precisamente una "elección política» (no una obligación impuesta por la situación de hecho: Romboli, 2013), resulta reforzada la exigencia de un control que garantice eficazmente la observancia de esos principios. Ya que, aun admitiendo que el equilibrio y la sostenibilidad presupuestarios constituyen fines para el legislador, no deja de ser relevante, desde una perspectiva «sistémica», relativa a la implementación del ordenamiento constitucional en su conjunto, la manera de perseguir tales fines (Romboli, 2013).

\section{ORIENTACIONES GENERALES}

Antes de valorar el impacto de la reforma de 2012 en las decisiones de la Corte costituzionale sobre medidas de estabilización financiera que han afectado a las rentas de los trabajadores y de los jubilados en el contexto de la crisis actual, es útil destacar algunas orientaciones generales que se deducen de la jurisprudencia constitucional reciente.

En primer lugar, se nota cierta continuidad respecto de la anterior jurisprudencia en materia de ponderación entre derechos y estabilidad financiera. La Corte ha reiterado la doctrina de los derechos sociales prestacionales como «derechos financiariamente condicionados», siempre y cuando el legislador observe el principio de igualdad-razonabilidad y no afecte al contenido esen- 
cial del derecho. Una novedad, cuya importancia es más simbólica que práctica, es la expresa calificación como tal del derecho a las prestaciones sanitarias, en la Sentencia 248/2011. Eso no implica discontinuidad en lo esencial: el uso de la «nueva» expresión se acompaña a la cita de la jurisprudencia anterior y deriva como consecuencia obvia de la reiterada constatación que «la exigencia de asegurar la universalidad y la completud del sistema asistencial en nuestro país afronta la escasez de los recursos que se pueden asignar anualmente, en el marco de una programación general de las intervenciones asistenciales y sociales, al sector sanitario» ${ }^{13}$.

Como en el pasado, solo pocas decisiones valorizan la noción de «contenido esencial». Su violación se ha reconocido en unas sentencias sobre disposiciones que limitaban la protección de los derechos de los discapacitados graves o garantizaban una protección considerada inadecuada: así se ha proseguido un camino emprendido hace mucho tiempo ${ }^{14}$. Destaca la Sentencia 80/2010, sobre el derecho a la integración escolar: tras afirmar la exigencia de asegurar un «núcleo indefectible de garantías» en favor de los discapacitados, como "límite no traspasable por la normativa discrecional del legislador», se han declarado ilegítimas algunas disposiciones ${ }^{15}$ en la parte en que, fijando un techo máximo de horas de docencia de apoyo, implicaban la imposibilidad de valerse de enseñantes especializados capaces de mejorar la situación de los discapacitados graves en el ambiente social y escolar, derogando la ratio entre estudiantes y docentes establecida por la normativa estatal ${ }^{16}$.

Es notable la referencia a las exigencias de protección del núcleo incompresible de la dignidad humana en las Sentencias 10/2010 y 62/2013, sobre la llamada "carta acquisti», medida de lucha contra la pobreza extrema regulada por decreto-ley por los Gobiernos Berlusconi y Monti. No obstante, dicha referencia ${ }^{17}$ no se hace para afirmar la preeminencia de las exigencias

13 Sentencia 111/2005, citada en la Sentencia 248/2011.

14 Véase Sentencia 215/1987.

15 Art. 2, par. 413 y 414, Ley 244/2007.

16 Para garantizar la "plena protección de los discapacitados graves» (que supone «la continuidad de las relaciones constitutivas de la personalidad humana»), la Corte ha seguido extendiendo el derecho al permiso extraordinario para asistirles, originalmente reconocido solo a los padres, a otros familiares conviventes, mediante pronunciamientos aditivos (Sentencias 203/2013, 19/2009, 158/2007, 233/2005).

17 Puede reconocerse cierta influencia del Bundesverfassungsgericht: en concreto de la Sentencia de 9 de febrero de 2010 sobre algunas previsiones de la reforma «Hartz IV», declaradas ilegítimas porque introducían, para el cálculo de unas ayudas sociales, criterios inadecuados para garantizar el derecho fundamental a un mínimo vital (fundado en los principios de dignidad humana y Estado social: arts. 1.1 y 20 LF). 
de protección del derecho a la asistencia social respecto a las consideraciones financieras, sino para legitimar (junto con la referencia a la crisis y a la carente implementación del art. $119 \mathrm{CI}$, en materia de autonomía financiera) una interpretación extensiva de la competencia legislativa estatal para determinar los niveles esenciales de las prestaciones (art. 117.2, $m$ CI) y la correspondiente compresión de la autonomía regional. Tampoco la Corte ha especificado cuál es la exacta relación entre la noción de contenido esencial de los derechos constitucionales y dicha competencia estatal, introducida por la reforma constitucional de 2001 (sobre su alcance véase Masala, 2014a: 187-276, vol. I). Desde hace años el legislador estatal sigue limitando fuertemente la autonomía regional, especialmente en los sectores del Estado de bienestar. Sin embargo, salvo raras excepciones (como las ahora mencionadas, controvertidas debido a la escasa eficacia de las medidas), el fin es la contención del gasto. La Corte costituzionale, aunque en principio ha excluido que la crisis financiera conlleve un «estado de excepción» que puede justificar la derogación del orden constitucional de competencias ${ }^{18}$, ha avalado la tendencia centralizadora, especialmente mediante la interpretación extensiva de la competencia estatal sobre los principios fundamentales de coordinación de la gestión de las finanzas públicas (art. 117.3 CI). Confirmando una orientacón consolidada, se ha reconocido la contención del gasto sanitario como uno de tales principios, y así no solo se ha justificado la limitación de la autonomía regional por leyes estatales, sino también se han declarado ilegítimas normas regionales que habían previsto exenciones o un incremento de servicios y prestaciones (Masala, 2014a: 319-352, vol. I) ${ }^{19}$.

Merece la pena recordar, por último, unos principios afirmados en la Sentencia 119/2012. La Corte ha excluido que le pertenezca (al controlar la constitucionalidad de una norma "de privilegio", que favorece a una determinada categoría de pensionistas) establecer el punto de ponderación entre los principios del art. $38 \mathrm{CI}$ y el principio de solidaridad social subyacente de las exigencias de contención del gasto y sostenibilidad del sistema de seguridad social, puesto que solo el legislador puede hacerlo, «teniendo en cuenta los

18 Sentencia 40/2012.

19 Sentencias 325/2011, 32/2012, 91/2012, 104/2013. La Sentencia 115/2012 ha declarado ilegítimas, por violar el art. $81.4 \mathrm{CI}$, normas regionales que no habían indicado precisamente la cobertura de nuevos servicios. La Sentencia 236/2012 ha afirmado que el legislador regional puede limitar la libertad de elegir al prestador de asistencia para conseguir un ahorro de gasto. Son más raras las decisiones que justifican intervenciones regionales con referencia a la inactividad del legislador estatal (por falta de determinación de los niveles esenciales de asistencia social: Sentencias 296/2012, 36/2013). 
recursos disponibles y los gastos asignables para el disfrute de los derechos relacionados con la asistencia y la seguridad social $\aleph^{20}$. Asimismo ha confirmado, en primer lugar, que «el art. $38 \mathrm{CI}$ no excluye la posibilidad de intervenciones legislativas que, por una inderogable exigencia de contención del gasto público, reduzcan tratamientos asegurados por leyes anteriores [...], sin prejuicio del control de razonabilidad de cada norma reductora»; en segundo lugar, que le pertenece «asegurar la salvaguardia del núcleo esencial de los derechos fundamentales que sean afectados por intervenciones reductoras ${ }^{21}$.

\section{DECISIONES SOBRE MEDIDAS DE AUSTERIDAD}

En estos años la Corte costituzionale ha controlado la constitucionalidad de medidas de estabilización financiera, adoptadas mediante decreto-ley en la pasada legislatura, que han afectado a las rentas de los empleados públicos y de los pensionistas. El control de razonabilidad ha tenido resultados diferentes en los varios casos examinados.

En una primera fase, la Corte ha declarado ilegítimas algunas medidas temporales, como el bloqueo de la adecuación automática del tratamiento económico de los magistrados, la reducción de la indemnización del mismo colectivo, la reducción del tratamiento económico de los empleados públicos con renta superior a un nivel determinado (Sentencia 223/2012 22); y como la

20 Fundamento 6.

21 En cambio cabe excluir — bajo pena de «confundir los papeles» («en desacuerdo con el sistema constitucional»)—_ «que la propia Corte costituzionale pueda decidir tales reducciones del gasto para implementar los derechos del art. $38 \mathrm{CI}$, en nombre de un genérico principio de solidaridad social, superando e incluso oponiéndose a las determinaciones del legislador». En definitiva, «solo a este pertenecen las determinaciones de política económica sobre los recursos disponibles». Pero la Corte reivindica para sí misma el poder de ejercer, en las formas indicadas, el control sobre dichas «determinaciones», cuando tengan efectos «reductores».

La sentencia ha juzgado ilegítimas medidas introducidas por el art. 9, Decreto-Ley $78 / 2010$. En cuanto al bloqueo trienal del incremento automático de las retribuciones de los magistrados, tras reiterar que dicho incremento tiene la función de salvaguardar la independencia del poder judicial, la Corte recuerda que «en ocasión de pasadas intervenciones de programación económica que implicaban derogaciones temporales» («particularmente, con ocasión de la grave coyuntura económica de 1992») había "ya indicado los límites dentro de los que una intervención de ese tipo puede considerarse respetuosa de los principios» constitucionales (Ordenanza 299/1999; Sentencias 245/1997 y 99/1995); tales límites «resultan irrazonablemente superados», porque la intervención afecta a una sola categoría de empleados y su duración es 
llamada «contribución de solidaridad» de los pensionistas con un tratamiento más elevado (Sentencia 116/2013 ${ }^{23}$ ). Las causas fundamentales de irrazonabilidad de dichas medidas regresivas son dos: la injustificada disparidad de trato en perjuicio de los colectivos afectados (respecto del conjunto de los empleados públicos o de los ciudadanos, en situación de paridad de renta y capacidad contributiva: de ahí la lesión de los arts. 3 y $53 \mathrm{CI}$ ); su duración (trienal) mayor que la de medidas parecidas ya adoptadas y juzgadas admisibles. Además, las medidas que afectaban a la renta de los magistrados se han considerado lesivas de los principios de autonomía e independencia del poder judicial (arts. 104 y $108 \mathrm{CI}$ ).

Todo eso significa una evidente continuidad respecto de las orientaciones definidas en la década de los 90, particularmente en lo referido a los criterios del control de razonabilidad de las medidas «excepcionales». No obstante, hay una discontinuidad que es igualmente evidente en cuanto a los resultados: la aplicación de esos mismos criterios conduce a declarar ilegítimas medidas regresivas que, a diferencia de las consideradas admisibles en el pasado, no cumplen con los requisitos de temporalidad y de no arbitrariedad, pues no son justificables ni en el contexto de crisis. No hay autolimitación, sino una reacción de la Corte, que subraya la existencia de límites cuyo respeto se impone a la discrecionalidad legislativa incluso en la emergencia económica: tras especificar que "la excepcionalidad de la situación económica a la que el Estado se enfrenta [...] puede sin duda permitir al legislador el uso de medidas excepcionales, para conciliar la salvaguardia de los intereses financieros con la

«solo aparentemente» limitada, debido a medidas análogas adoptadas anteriormente (fundamento 11). La reducción trienal de la indemnización de la Ley 27/1981 se considera una medida fiscal lesiva de los arts. 3 y $53 \mathrm{CI}$ porque (incidiendo «en una específica cuota de la renta laboral, que es parte de la renta laboral total ya sujeta a imposición») introduce "un elemento de discriminación solo en perjuicio de la categoría» (fundamento 12). En cuanto a la reducción trienal de los tratamientos económicos de los empleados públicos superiores a 90000 euros brutos, "la introducción de un impuesto especial, aunque transitorio y excepcional [...] viola el principio de igualdad de imposición», resultando irrazonable (fundamento 13).

23 La decisión ha declarado ilegítima una disposición del Decreto-Ley 98/2011, de nuevo a partir del principio que el art. $53 \mathrm{CI}$ «no permite tratos in pejus de determinadas categorías de rentas laborales». Tras constatar que, al recaudar «recursos para la estabilización financiera, el legislador ha decidido tratar diversamente las rentas de los pensionistas» (ya que "la contribución de solidaridad se aplica para techos [de renta] inferiores y con porcentajes superiores» respecto de las previstas para los otros ciudadanos), la «injustificada limitación de los sujetos pasivos» determina el «juicio de irrazonabilidad y arbitrariedad» (fundamento 7.3). 
garantía de las prestaciones y de la protección que todos los ciudadanos necesitan", se confirma que «sin embargo, es una tarea del Estado la de garantizar, también en estas condiciones, la observancia de los principios fundamentales del ordenamiento constitucional, que, ciertamente, no es indiferente a la realidad económica y financiera, pero con igual certeza no puede permitir derogaciones del principio de igualdad, fundamento del ordenamiento constitucional $»^{24}$.

Tras las polémicas suscitadas por estas sentencias ${ }^{25}$, otras decisiones han conllevado un «repliegue». La Corte ha redefinido los criteros del control de razonabilidad de las medidas «excepcionales» y concretamente ha «actualizado» el requisito de temporalidad, de tal manera que ha salvado algunas de dichas medidas de la declaración de inconstitucionalidad. La nueva dirección jurisprudencial ha sido inaugurada por la Sentencia 310/2013, que ha justificado las disposiciones que habían previsto el bloqueo trienal del incremento de las retribuciones de los profesores e investigadores universitarios ${ }^{26}$. En los fundamentos, la Corte trae a colación la «evolución sobrevenida en el marco global, jurídico y económico, nacional y europeo»: en particular, los nuevos arts. 81, 97 y 119.1 CI, reformados en 2012, que "ponen el acento en el cumplimiento del equilibrio presupuestario por parte de las administraciones públicas, también a la luz del más amplio contexto económico europeo»; y las nuevas reglas europeas de coordinación de las políticas presupuestarias ${ }^{27}$. La

24 Sentencia 223/2012, fundamento 13.3; Sentencia 116/2013, fundamento 7.3.

25 Criticadas por quienes han estimado que los «sacrificios» juzgados irrazonables habrían sido justos (porque las medidas afectaban a categorías no necesitadas, sin interesar el contenido esencial de los derechos de los arts. 36 y $38 \mathrm{CI})$. En su memoria de 2013 el presidente de la Corte subraya que el fundamento de la Sentencia 116/2013 es el «principio elemental» derivado de los arts. 3 y 53 CI «conforme al cual sobre rentas iguales hay que aplicar igual imposición fiscal», «verdad» que no puede ser empañada por un «clamor político o mediático». Desde luego, en ambas sentencias la Corte había especificado que el «resultado presupuestario habría podido ser bien más favorable para el Estado, si el legislador hubiera observado los principios de igualdad de los ciudadanos y de solidaridad económica, también modulando diversamente un tratamiento impositivo 'universal'» (Sentencia 223/2012, fundamento 13.3; Sentencia $116 / 2013$, fundamento 7.3).

26 Otras normas del Decreto-Ley 78/2010.

27 La Corte advierte que la Directiva 2011/85/UE, sobre requisitos para los marcos presupuestarios aplicables a los países de la zona del euro, «evidencia que 'la gran parte de las medidas financieras tienen implicaciones presupuestarias que transcienden el ciclo presupuestario anual' y concluye que 'una perspectiva anual no constituye pues una base adecuada para políticas presupuestarias sólidas'», puesto que «las medidas 
atención a estos elementos — que diferencian el contexto actual de los años noventa - conduce a reconocer la «razonabilidad del desarrollo temporal de las medidas». El espacio para el legítimo ejercicio de la discrecionalidad legislativa es así ampliado. Puesto que «la contención y la racionalización del gasto público, mediante las cuales puede llevarse a cabo una política de recuperación del equilibrio presupuestario, conllevan sacrificios gravosos, como los ya examinados, que encuentran justificación en la situación de crisis económica», la Corte especifica que «en particular, a la luz de las necesarias actuales perspectivas plurianuales del ciclo presupuestario, tales sacrificios pueden referirse a periodos, ciertamente determinados, pero más largos» respecto a aquellos, considerados razonables en el pasado, previstos por la programación presupuestaria de 1992. Por otro lado, contribuye a fundar la desestimación la (no) especificidad del colectivo afectado: ya que en este caso no debe salvaguardarse la independencia del poder judicial. En definitiva, las normas impugnadas superan el control de razonabilidad, "porque son dirigidas a un ahorro de gasto que afecta al conjunto de los empleados públicos, en una dimensión solidaria - aun con las diferenciaciones exigidas por los diferentes estatutos profesionales de los colectivos pertenecientes al conjunto- - y por un período limitado, que comprende más años a la luz de la programación plurianual de las políticas presupuestarias ${ }^{28}$.

Posteriormente, con dos Sentencias muy controvertidas debido a su caracter innovador (10/2015) y a su impacto presupuestario (70/2015), la Corte ha vuelto a fallar declaraciones de ilegitímidad de normas aprobadas para la estabilización financiera en el contexto de la crisis. Pero entre dichas decisiones hay una diferencia fundamental, explicable, al menos en parte, por la diversidad de las normas impugnadas.

La Sentencia 10/2015 ha limitado la eficacia retroactiva de la declaración de inconstitucionalidad de un impuesto especial que afectaba a una categoría particular de personas jurídicas, estableciendo que dicha declaración tendría efectos a partir del día siguiente a su publicación ${ }^{29}$. Por primera vez la Corte ha afirmado con claridad su poder de modular los efectos temporales de sus decisiones estimatorias, para tener en cuenta el impacto de estas en principios

estructurales de ahorro de gasto no deben prescindir de las políticas económicas europeas» (fundamento 13.4).

28 Cons. 13.5. Además de la Sentencia 310/2013 (confirmada por la Ordenanza 113/2014), los mismos argumentos han fundado otras Sentencias desistimatorias (154 y 219/2014).

29 La Corte ha considerado lesivo de los arts. 3 y 53 CI un impuesto especial adicional sobre la renta de las sociedades petroleras y gasísticas con ganancias anuales superiores a los 25 millones de euros, introducido por el Decreto-Ley 112/2008. 
constitucionales diferentes de los violados por las normas declaradas ilegítimas. Éste es un poder que no está previsto ni por la Constitución ni por la ley, y que siempre ha encontrado objeciones por una parte de la doctrina (Anzon, 2015). En el supuesto examinado, la limitación de los efectos de la decisión de inconstitucionalidad ha sido justificada, ante todo, haciendo referencia a una necesaria ponderación con el principio de equilibrio presupuestario («nuevo» art. $81 \mathrm{CI}$ ). Según la Corte la aplicación retroactiva de la sentencia habría determinato «una grave violación» de dicho principio, causando «un desequilibrio del presupuesto estatal tan importante que requeriría una programación presupuestaria adicional, también para asegurar el cumplimiento de los parámetros a los que Italia se ha obligado a nivel de la Unión Europea e internacional», que vinculan al legislador conforme al art. 117 CI. Además, la decisión ha hecho referencia a exigencias de solidaridad social, fundadas en los arts. 2 y 3 CI.

En cambio, la Sentencia 70/2015 ha declarado inconstitucional (por violar los principios de solidaridad, razonabilidad e igualdad sustancial y el derecho a una pensión proporcionada y adecuada: arts. 36 y 38.2 CI) el art. 24, par. 25 del Decreto-Ley 201/2011, que había dispuesto, para 2012 y 2013, el bloqueo total del mecanismo automático de revalorización de las pensiones cuyo importe es superior a tres veces el mínimo. Sin embargo, la Corte no ha modulado los efectos temporales de la decisión, ni ha mencionado el art. 81 CI. En este caso, (implicitamente) ha estimado que el principio de equilibrio presupuestario no era suficiente para justificar la limitación de la eficacia retroactiva de la declaración de incostitucionalidad. Debido a su impacto en las finanzas públicas, la decisión ha suscitado duras críticas de unos sectores del mundo político y de una parte de la doctrina (Barbera, 2015), además de la preocupación de la Comisión Europea ${ }^{30}$.

Las razones que han inducido la Corte costituzionale a declarar ilegítimo el bloqueo de la revalorización automática de las pensiones superiores a tres veces el mínimo dispuesto en 2011 resultan claras si se consideran la diferencias entre dicha medida y el bloqueo del mecanismo de revalorización dispuesto en 2007 y considerado legítimo por la Sentencia 316/2010, precedente analizado detalladamente en la Sentencia 70/2015. En primer lugar, el «viejo» bloqueo había afectado solo a las pensiones superiores a ocho veces el mínimo (pensiones cuyo importe era sin duda elevado); mientras que el más reciente

30 Incluso hubo una polémica entre el ministro de Economía y Finanzas y el presidente de la Corte, mediante entrevistas a un periódico nacional: empezó el ministro, lamentando la falta de coordinación entre Corte y Gobierno y reprochando a la primera no haber considerado el impacto económico del pronunciamiento; luego el presidente defendió la conducta de la Corte. 
afectaba también a pensiones cuyo importe era relativamente modesto. En segundo lugar, la nueva medida afectaba igualmente (bloqueando totalmente la revalorización) a todas las pensiones interesadas; mientras que anteriormente el legislador había distinguido diferentes clases de importe, graduando de manera correspondiente la incidencia del bloqueo. En tercer lugar, mientras que el bloqueo dispuesto en 2007 había sido considerado razonable también por su duración anual, el bloqueo dispuesto en 2011 era bienal; además el legislador no había tenido en cuenta la advertencia pronunciada en la Sentencia 316/2010, según la cual la frecuente reiteración de medidas dirigidas a paralizar el mecanismo de revalorización habría implicado la violación de los principios de razonabilidad y proporcionalidad. Por último, la Corte ha reprochado al legislador no haber motivado adecuadamente el sacrificio del derecho a una pensión proporcionada y adecuada (derivado del «interés de los pensionistas, en particular de los que disfrutan de tratamientos modestos», «a la conservación del poder adquisitivo de los importes percibidos»). En concreto, no se ha considerando suficiente a este fin una genérica referencia a la situación financiera y esta falta de motivación ha fundado la conclusión que ese derecho había sido «irrazonablemente sacrificado en nombre de exigencias financieras no ilustradas en detalle» (mientras que en 2007 se había evidenciado la finalidad solidaria y redistributiva del bloqueo).

La comparación con la Sentencia 10/2015 permite establecer hipótesis acerca de las razones, no especificadas, por las que la Corte al dictar la Sentencia 70/2015 no ha modulado los efectos temporales de una declaración de incostitucionalidad que ha implicado cargas presupuestarias significativas. De nuevo, destaca la diferencia entre las disposiciones impugnadas. Ambas tenían una finalidad de estabilización financiera. Pero la medida declarada ilegítima por la Sentencia 10/2015 perseguía este fin mediante un impuesto especial sobre ganancias "extraordinarias» de sujetos económicamente fuertes, mientras que la Sentencia 70/2015 ha declarado ilegítima una medida que afectaba a las pensiones, incluso algunas de importe relativamente bajo. Por lo tanto, en el segundo caso la limitación de la eficacia retroactiva de la declaración de inconstitucionalidad no habría podido fundarse en las exigencias de solidaridad social e igualdad que en la sentencia 10/2015 concurren a justificarla. Dicha limitación se habría producido en contradicción con tales exigencias, que han fundado la decisión de inconstitucionalidad del bloqueo de la revalorización. Además la duración de esta medida era definida, puesto que se refería a dos anualidades ya pasadas en el momento de la decisión, mientras que la duración del impuesto adicional objeto de la Sentencia 10/2015 era indeterminada. En consecuencia, en casos como el de la Sentencia 10/2015 la limitación de la eficacia de la decisión pro praeterito no excluye que la misma decisión tenga eficacia pro futuro. Al contrario, en el caso de la Sentencia 70 excluir la 
eficacia retroactiva de la decisión de inconstitucionalidad habría significado su total ineficacia. Así se habría formado un precedente que habría «instigado» al legislador a disponer nuevas medidas lesivas de un derecho social constitucional, de duración limitada a algunas anualidades, con el efecto de privar de efectividad a las disposiciones constitucionales en materia de derechos. Además, cabe recordar que la Sentencia 316/2010 contenía un llamamiento al legislador, para que este no reiterara el bloqueo de la revaluación. Por último (Barbera, 2015), probablemente, después de la Sentencia 223/2012, que había declarado inconstitucional, sin modular los efectos temporales, la "contribución de solidaridad» que afectaba a las "pensiones de oro», la Corte ha considerado que habría sido injusto limitar los efectos de la declaración de inconstitucionalidad de una medida que afectaba (también) a pensiones de importe muy inferior.

Tras las polémicas suscitadas por la Sentencia 70/2015, la Corte ha resuelto otra cuestión de constitucionalidad planteada sobre otra medida de austeridad adoptada en el contexto de la crisis: la congelación de los retribuciones de los empleados públicos, causada por el bloqueo de la contratación colectiva en el sector desde 2011. La Sentencia 178/2015 ha juzgado ilegítimo dicho bloqueo, derivado dal conjunto de las normas impugnadas ${ }^{31}$ y de normas posteriores que lo habían prorrogado, en la parte económica, hasta finales de $2015^{32}$. La reiterada prórroga de la suspensión de la contratación económica, que ha hecho «estructural» el bloqueo, ha sido juzgada lesiva del principio de libertad sindical (art. $39 \mathrm{CI})^{33}$. En este caso la Corte ha pronunciado una declaración de ilegitimidad constitucional sobrevenida, con efectos a partir del día siguiente a la publicación de la sentencia, «sin prejuicio, para el período ya transcurrido, de los efectos económicos derivados de la regulación examinada». Frente a un dilema semejante al que se había presentado a

31 Art. 9, par. 1 y 2, Decreto-Ley 78/2010, que había dispuesto un bloqueo trienal; art. 16, par. 1, Decreto-Ley 98/2011, que había autorizado su prórroga hasta finales de 2014.

32 Art. 1, par. 456 y 457, ley 147/2013 y art. 1, par. 254 y 255, Ley 190/2014.

33 Fundamentos 15 y 16. En cambio, el control de razonabilidad conforme a los requisitos conocidos ha excluido la violación de los arts. 3.1 y 36 CI. A pesar de que el bloqueo se aplicara para un período superior no solo al año considerado razonable por la Sentencia 245/1997, sino también al trienio considerado razonable por la Sentencia 310/2013, la Corte ha estimado razonable (a la luz del carácter plurianual de las políticas presupuestarias, de la «particular gravedad de la situación económica y financiera», y del carácter sostenido de la dinámica retributiva en el sector público antes del bloqueo) la limitación del derecho a una retribución suficiente y proporcionada (fundamentos 10-14). 
la hora de juzgar el bloqueo de la revalorización de las pensiones, la solución ha sido diferente. Se puede suponer que la decisión de excluir toda aplicación retroactiva de la declaración de inconstitucionalidad y la consiguiente diferencia de trato entre empleados públicos y pensionistas no han derivado (o no han derivado solo) de la evaluación del impacto económico de una eventual declaración de inconstitucionalidad referida también al pasado ${ }^{34}$. De hecho, parecen haber sido relevantes, también en este caso, las peculiaridades de la medida considerada: en particular, la circunstancia que la «naturaleza estructural» de la suspención de la contratación, que ha hecho intolerable el sacrificio de la libertad sindical, se ha «manifestado en su plenitud» solo tras las reiteradas prórrogas; y la circunstancia que en este caso el bloqueo seguía siendo aplicado al momento de la decisión ${ }^{35}$. Como consecuencia, en el caso más reciente la declaración de inconstitucionalidad solo pro futuro ha tenido el efecto concreto de poner fin al bloqueo ${ }^{36}$.

\section{CONCLUSIONES}

El análisis de la jurisprudencia constitucional sobre las «intervenciones reductoras» realizadas durante la reciente crisis económica permite reconocer una continuidad básica, en cuanto a los esquemas de control y a las estrategías argumentativas, respecto de las decisiones pronunciadas en los años noventa referidas a intervenciones análogas. Como en el pasado, la Corte costituzionale ha sometido a control de razonabilidad las innovaciones legislativas, averiguando que estas tuvieran duración limitada y no implicaran disparidades de trato injustificadas. Sin embargo, la aplicación de los criterios de enjuiciamiento ya probados ha producido, en una primera fase, resultados opuestos a los habituales. Si antes la regla había sido la justificación de las medidas que

34 Y de las polémicas posteriores a la Sentencia 70/2015, que podrían haber inducido a la Corte a autolimitarse. Significativamente en la Sentencia 178/2015 se vuelve a mencionar el «nuevo» art. $81 \mathrm{CI}$ (fundamentos 10.3 y 17).

Fundamentos 17 y 18 .

36 Así la reapertura de las negociaciones con los sindicatos para incrementar las retribuciones. Así, limitar la eficacia retroactiva no excluye todo impacto económico, pero dicho impacto queda contenido. Parece pues que en el caso más reciente la Corte ha podido buscar una conciliación entre las exigencias de protección de los derechos y la exigencia de asegurar la estabilidad financiera por medio de una solución que no se podía aplicar con efectos iguales en el caso de la Sentencia 70 (ya que habría significado sacrificar drasticamente los derechos de los pensionistas, aun tras la advertencia de la Sentencia 316/2010). 
afectaban a las rentas de los trabajadores y pensionistas, la Corte ha declarado ilegítimas algunas de las intervenciones más recientes, considerando que estas habían traspasado los límites ya definidos y subrayando que también en una situación de crisis debe asegurarse el cumplimiento de los «principios fundamentales del ordenamiento constitucional». Así, se ha vuelto a poner el problema de los efectos de las sentencias constitucionales "costosas" por proteger derechos sociales prestacionales. Con la diferencia de que con anterioridad los costes eran originados especialmente por sentencias aditivas, que extendían la protección; mientras que hoy las «mayores cargas» derivan de sentencias ablativas, que, declarando inconstitucionales medidas regresivas, implican restituciones a sujetos cuyas rentas fueron reducidas (además de menores ahorros de gasto o menores ingresos para el futuro, cuando la medida continue a aplicarse en el momento de la decisión).

Luego, al persistir la crisis, la Corte ha redefinido parcialmente los criterios del control de razonabilidad a la luz de algunas peculiaridades del nuevo contexto, tal y como había ocurrido hace dos décadas, cuando la consideración de los condicionamientos derivados del proceso de integración europea contribuyó a fundar su decisión de «salvar» algunas medidas «excepcionales». La referencia al principio de equilibrio presupuestario (arts. 81 y $119 \mathrm{CI}$ reformados en 2012) y a las reglas de la nueva gobernanza económica europea constituyen el fundamento que justifica unas medidas regresivas recientes, cuya aplicación se había previsto para períodos superiores a los considerados razonables anteriormente. Además, la Corte ha afirmado su poder para limitar la eficacia retroactiva de sus decisiones estimatorias, en concreto para contener el impacto de estas en el equilibrio presupuestario y en la capacidad de cumplir con los parámetros europeos. Pero este poder, aplicado a la hora de declarar ilegítimo un impuesto que afectaba a sujetos económicamente muy fuertes, no ha sido utilizado en la Sentencia 70/2015 sobre las pensiones, mientras que en la Sentencia 178/2015, sobre las retribuciones de los empleados públicos, se ha vuelto a pronunciar una declaración de inconstitucionalidad eficaz solo pro futuro.

En definitiva, puede advertirse que, tal y como sucedía en el pasado, empujada por el nuevo contexto, la Corte costituzionale ha «actualizado»su doctrina (extendiendo el plazo del razonable desarrollo temporal de las medidas excepcionales) y ampliado el listado de las técnicas decisorias a su disposición, buscando nuevos instrumentos para conciliar la protección de los derechos y el cumplimiento de los principios de igualdad y solidaridad con la salvaguardia de la estabilidad financiera y el cumplimiento de los compromisos europeos. La dificultad de reconocer una coherencia completa en la jurisprudencia constitucional reciente en parte depende de las diferencias entre las medidas examinadas, pero también parece ser el reflejo de las difi- 
cultades que la Corte costituzionale encuentra para desarrollar esta tarea tan delicada en el nuevo marco económico y jurídico. La impresión general es que estamos asistiendo a un proceso de "readaptación», complicada y todavía en curso. No todos los nuevos caminos recorridos por la Corte llegan al mismo destino: unos conducen a justificar las intervenciones reductoras o a contener el coste de la declaración de su inconstitucionalidad; mientras que en otros casos ha habido una reacción frente a la compresión de los derechos (a pesar del impacto considerable de dicha reacción en las finanzas públicas). En particular, la Sentencia 70/2015 puede mirarse como un paso hacia la superación de los límites tradicionales del control de razonabilidad entendido como control de coherencia interna de la legislación, ya que, inusualmente, reconoce la lesión de parámetros «sustanciales»; y que, lamentando la falta de una adecuada motivación del sacrificio impuesto (y subrayando en cambio que la Sentencia 316/2010 había juzgado razonable una intervención de la cual se había indicado las finalidad solidaria y redistributiva), deja entender que el legislador, al perseguir la estabilidad financiera, debe siempre orientarse no solo por el principio de igualdad-razonabilidad, sino también por un criterio de una más estricta proporcionalidad y por el conjunto de los "principios fundamentales del ordenamiento constitucional», que incluyen la igualdad sustancial, la solidaridad y la salvaguardia de los derechos sociales. En este sentido puede estimarse que la Corte no ha ignorado completamente las sugerencias de quienes (Carlassare, 2013: 12) habían insistido en que es necesaria una visión sistémica, la cual supone entender la razonabilidad como "coherencia con los principios constitucionales» (al menos frente a "prioridades constitucionales ciertas", que permiten delimitar con suficiente claridad el espacio del control de constitucionalidad). Por último, puede advertirse que en las decisiones sobre las recientes medidas de austeridad la Corte no ha aclarado qué hay que considerar «esencial» (qué parte de un derecho no puede sacrificarse), sino que ha precisado cómo el legislador debe intervenir para que las normas dirigidas a salvaguardar la estabilidad financiera superen el control de razonabilidad ${ }^{37}$. Desde lue-

37 Es controvertida la posibilidad de que, cuando la Corte haya dictado una declaración de inconstitucionalidad de una medida regresiva sin limitar su eficacia retroactiva, el legislador "reabra la partida», adoptando una nueva regulación retroactiva (también regresiva pero conforme a los requisitos de razonabilidad derivados del pronunciamiento) para reducir el «coste» de la decisión. El Gobierno, para pretendidamente «cumplir los principios enunciados en la Sentencia [70/2015] y a la vez salvaguardar los equilibrios presupuestarios y de finanza pública», ha aprobado, mediante Decreto-Ley (65/2015), una nueva regulación del bloqueo para 2012 y 2013: previendo, únicamente para los pensionistas cuyo tratamiento es inferior o 
go, parecía difícil reconocer, en los casos examinados, lesiones evidentes del núcleo esencial de los derechos de los arts. 36 y 38 CI. Sin embargo, en el caso particular de la Sentencia 70/2015 la Corte ha puesto el énfasis en que el legislador hubiera sacrificado también y "particularmente», los derechos de "perceptores de pensiones modestas» y eso supuestamente contribuye a explicar la especificidad de dicha decisión.

Una comparación entre las orientaciones de la Corte italiana y las de los tribunales constitucionales de otros Estados europeos en los que se han implementado políticas de austeridad, supera los límites de este análisis. Sin embargo, considerando los dos casos más cercanos y aprovechando otros estudios, puede advertirse, en general, que la actitud de los magistrados de la Corte costituzionale ha sido más reactiva y menos deferente que la de sus omólogos españoles; $y$, aun teniendo en cuenta las recordadas decisiones estimatorias, parece que sería impropio hablar de activismo judicial tal y como se ha hecho - quizá tampoco correctamente- con referencia a la reciente jurisprudencia del Tribunal Constitucional portugués. A pesar de las diferencias (que derivan de las peculiaridades de los sistemas de justicia constitucional, pero también de la situación política y económica de cada país y de la composición de cada Tribunal en este momento histórico), puede oservarse un elemento común fundamental: cuando ha habido una «reacción» a las medidas de austeridad, la declaración de inconstitucionalidad se ha fundado casi siempre en la comprobación de una violación de los principios de razonabilidad o proporcionalidad, mientras que son mucho más raros los casos en los que tal declaración se ha fundado en la violación del principio de igualdad sustancial o de los derechos sociales (aunque estos han sido frecuentemente indicados como parámetros en los recursos de inconstitucionalidad). Este enfoque común (que desde luego implica continuidad respecto de la jurisprudencia de los mismos tribunales anterior a la crisis), aunque no significa en sí deferencia, revela todavía una prudencia fundamental, que corresponde (Fasone, 2014)

igual a seis veces el mínimo, una restitución parcial y una tantum, de entidad variable según diferentes clases de importe. Sin embargo es lícito dudar de la suficiencia de esta intervención "correctiva» para cumplir la sentencia y puede plantearse una violación del «juzgado constitucional» (art. $137 \mathrm{CI}$ ). La previsión de un bloqueo modulado «por clases» según criterios de progresividad parece coherente con las indicaciones de la Sentencia 70/2015. Sin embargo (ya que la Corte no había autorizado expresamente al Gobierno a volver a intervenir para el pasado, sino que había insistido en la exigencia de evitar la reiteración de la medida) hay razones para dudar de que el legislador pudiera volver a regular el bloqueo para las anualidades pasadas y para creer, en cambio, que el Estado tenía que reembolsar íntegramente a todos los pensionistas afectados. 
ya sea a la voluntad de evitar, en la medida de lo posible, conflictos directos con el poder político, que a la exigencia de favorecer la mediación dentro de cada Corte. La superación de los límites que lo caracterizan requeriría no solo una voluntad que no está garantizada, sino también un esfuerzo que probablemente trasciende las posibilidades actuales de las Cortes constitucionales nacionales. Eso es lo que hacen pensar las reacciones políticas e institucionales ante esas decisiones que se han «atrevido» a declarar ilegítimas unas medidas de estabilización financiera.

A estas alturas, quienes creen que una actitud menos indulgente hacia la discrecionalidad legislativa estaría justificada de cualquier modo (por la exigencia de contener los costes sociales de la crisis, desproporcionados; y por el déficit de democraticidad de las medidas de austeridad y flexibilización laboral adoptadas en estos años), no pueden sino desear una cooperación más eficaz con los tribunales europeos supranacionales y que estos lleguen a jugar un papel más relevante como «contrapesos» respecto de los condicionamientos derivados de la nueva gobernanza económica. Desde esta perspectiva, si es sabido que el desarrollo del papel del Tribunal de Justicia de la UE supone la «comunitarización» de las reglas de la nueva gobernanza económica europea ${ }^{38}$, se ha advertido que unas indicaciones proceden ya de algunas decisiones del Tribunal Europeo de Derechos Humanos y del Comité Europeo de Derechos Sociales. Las primeras sugieren que las intervenciones reductoras deben ser graduales; las segundas (no vinculantes) han utilizado indicadores para medir la entidad de la violación de los derechos a la justa retribución de los trabajadores y pensionistas e inducen a exigir (por el legislador nacional y por las instituciones europeas) «rigurosas y previas evaluaciones del impacto de la regulación dirigida a hacer frente a la crisis, con referencia específica a su incidencia en los derechos sociales»: de modo que, en ausencia de tales evaluaciones, debería cargarse sobre el poder político la obligación de demostrar la inexistencia de medios alternativos (Guazzarotti, 2013).

\section{BIBLIOGRAFÍA}

Andreoni, A. (2006). Lavoro, diritti sociali e sviluppo economico. Torino: Giappichelli.

38 Para que las medidas nacionales de austeridad puedan considerarse actos de aplicación del derecho de la Unión y, conforme al art. 51 de la Carta de los Derechos Fundamentales de la UE, sea posible controlar su compatibilidad con las disposiciones de la misma Carta. 
Anzon, A. (2015). La Corte costituzionale «esce allo scoperto» e limita l'efficacia retroattiva delle proprie pronunzie di accoglimento. Rivista AIC, 2. Disponible en: http:// www.rivistaaic.it/la-corte-costituzionale-esce-allo-scoperto-e-limita-l-efficacia-retroattiva-delle-proprie-pronunzie-di-accoglimento.html.

Baldassarre, A. (1989). Diritti sociali. En Enciclopedia Giuridica, vol. XI (p. 1 y ss.). Roma: Istituto della Enciclopedia italiana.

Barbera, A. (2015). La sentenza relativa al blocco pensionistico: una brutta pagina per la Corte. Rivista AIC, 2. Disponible en: http://www.rivistaaic.it/la-sentenza-relativa-al-blocco-pensionistico-una-brutta-pagina-per-la-corte.html.

Benvenuti, M. (2013). Diritti sociali. Torino: Utet.

Butturini, D. (2014). Caratteri e tipologie delle sentenze additive di prestazione. En D. Butturini, M. Nicolini (eds.). Tipologie ed effetti temporali delle decisioni di incostituzionalità (pp. 47-83). Napoli: Editoriale scientifica.

Carlassare, L. (2013). Priorità costituzionali e controllo sulla destinazione delle risorse. Costituzionalismo.it, 1. Disponible en: http://www.costituzionalismo.it/artico$\mathrm{li} / 441 /$.

Ciolli, I. (2012). I diritti sociali al tempo della crisi economica. Costituzionalismo.it, 3. Disponible en: http://www.costituzionalismo.it/articoli/426/.

Colapietro, C. (1996). La giurisprudenza costituzionale nella crisi dello Stato sociale. Padova: Cedam.

Donati, F. (2013). Crisi dell'euro, governance economica e democrazia nell'Unione europea. Il Diritto dell'Unione Europea, 2, 337-361.

Fasone, C. (2014). Constitutional Courts Facing the Euro Crisis. Italy, Portugal and Spain in comparative perspective (EUI Working Paper MWP 2014/25). Disponible en: http://hdl.handle/1814/33859.

Giupponi, T. F. (2014). Il principio costituzionale dell'equilibrio di bilancio e la sua attuazione. Quaderni costituzionali, 1, 51-77.

Grasso, G. (2012). Il costituzionalismo della crisi. Napoli: Editoriale scientifica.

Guazzarotti, A. (2013). Crisi economica e ruolo delle corti: quali contrappesi alla governance europea e internazionale? Diritto pubblico, 3, 1011-1049.

Luciani, M. (1993). Art. 81 della Costituzione e decisioni della Corte costituzionale. En VV. AA., Le sentenze della Corte costituzionale e l'art. 81, u.c., della Costituzione (pp. 53-62). Milano: Giuffrè.

- (2013a). Costituzione, bilancio, diritti e doveri dei cittadini. Astrid Rassegna, 3. Disponible en: http://www.astrid-online.it/rassegna/2013/06_02_2013.html.

- (2013b). L'equilibrio di bilancio e i principi fondamentali. La prospettiva del controllo di costituzionalità, ponencia en el Cogreso Il principio dell'equilibrio di bilancio secondo la riforma costituzionale del 2012. Roma, 22 noviembre de 2013. Disponible en: http://www.cortecostituzionale.it/documenti/convegni_seminari/ Seminario2013_Luciani.pdf.

Masala, P. (2014a). La tutela dei diritti sociali negli ordinamenti di tipo composto tra uniformità e differenziazione (II vols.). Pisa: Pisa University Press.

- (2014b). La libertà di scelta del soggetto erogatore delle prestazioni sanitarie in tutto il territorio nazionale a prescindere dalla Regione di residenza e i suoi limiti. 
Federalismi.it, 22. Disponible en: http://www.federalismi.it/nv14/articolo-documento.cfm?Artid=28059.

- (2016). Ripercussioni della nuova governance europea collegata alla crisi economico-finanziaria sugli equilibri interni alla democrazia parlamentare, con particolare riferimento all'esercizio della funzione legislativa: il caso italiano. En F. Lanchester (ed.). Parlamenti nazionali e Unione europea nella governance multilivello (pp. 323372). Milano: Giuffrè.

Massa Pinto, I. (1998). La discrezionalità politica del legislatore tra tutela costituzionale del contenuto essenziale e tutela caso per caso dei diritti nella più recente giurisprudenza costituzionale. Giurisprudenza costituzionale, 2, 1309 y ss.

- (2001). Contenuto minimo essenziale dei diritti sociali e concezione espansiva della Costituzione. Diritto pubblico, 3. 1095 y ss.

Merusi, F. (1985), I servizi pubblici negli anni 80. Quaderni regionali, 54 ss.

Midiri, M. (2011). Diritti sociali e vincoli di bilancio nella giurisprudenza costituzionale. En M. Ainis y otros (eds.). Studi in onore di Franco Modugno, vol. III (pp. 22352275). Napoli: Editoriale scientifica.

Morana, D. (2013). I diritti a prestazione in tempo di crisi: istruzione e salute al vaglio dell'effettività. Rivista AIC, 4. Disponible en: http://www.rivistaaic.it/i-diritti-a-prestazione-in-tempo-di-crisi-istruzione-e-salute-al-vaglio-dell-effettivit.html.

Morrone, A. (2014a). Pareggio di bilancio e Stato costituzionale. Rivista AIC, 1. Disponible en: http://www.rivistaaic.it/pareggio-di-bilancio-e-stato-costituzionale.html.

- (2014b). Crisi economica e diritti. Appunti per lo stato costituzionale in Europa. Quaderni costituzionali, 1, 79-108.

Olivito, E. (2014). Crisi economico-finanziaria ed equilibri costituzionali: qualche spunto a partire dalla lettera della $\mathrm{BCE}$ al governo italiano. Rivista $A I C, 1$. Disponible en: http://www.rivistaaic.it/crisi-economico-finanziaria-ed-equilibri-costituzionali-qualche-spunto-a-partire-dalla-lettera-della-bce-al-governo-italiano.html.

Pizzorusso, A. (1993), Comunicazione. En VV. AA. Le sentenze della Corte costituzionale e l'art. 81, u.c., della Costituzione (pp. 347-354). Milano: Giuffrè.

Romboli, R. (2013). Derechos sociales fundamentales y libertades económicas frente a la crisis. En R. Escudero Rodríguez, J. Cano Bueso (eds.). Crisis económica y modelo social. La sostenibilidad del Estado de Bienestar (pp. 165-179). Almería: Editorial Universidad de Almería.

Salazar, C. (2000). Dal riconoscimento alla garanzia dei diritti sociali. Torino: Giappichelli.

- (2013). Crisi economica e diritti fondamentali. Rassegna parlamentare, 4, 785-833.

Spadaro, A. (2011). I diritti sociali di fronte alla crisi (necessità di un nuovo «modello sociale europeo»: più sobrio, solidale e sostenibile. Rivista $A I C$ (4). Disponible en: http://www.rivistaaic.it/i-diritti-sociali-di-fronte-alla-crisi-necessit-di-un-nuovo-modello-sociale-europeo-pi-sobrio-solidale-e-sostenibile.html.

VV. AA. (1993). Le sentenze della Corte costituzionale e l'art. 81, u.c., della Costituzione. Milano: Giuffrè. 